\title{
Impact of Nab-Paclitaxel-based Second-line Chemotherapy in Metastatic Pancreatic Cancer
}

\author{
NEELAKANTA DADI ${ }^{1}$, MELISSA STANLEY $^{1}$, SAFI SHAHDA ${ }^{1}$, BERT H. O’NEIL ${ }^{1}$ and AMIKAR SEHDEV ${ }^{1,2,3}$ \\ ${ }^{1}$ Division of Hematology and Oncology, Department of Medicine, \\ Indiana University School of Medicine, Indianapolis, IN, U.S.A.; \\ ${ }^{2}$ Center for Health Services Research, Regenstrief Institute, Indianapolis, IN, U.S.A.; \\ ${ }^{3}$ Richard M. Fairbanks School of Public Health, Indiana University, Indianapolis, IN, U.S.A.
}

\begin{abstract}
Background: Pancreatic ductal adenocarcinoma (PDAC) is a lethal malignancy with median survival of $20 \%$ at 1 year. We conducted a retrospective study to assess the efficacy and tolerability of nab-paclitaxel (NP)-based secondline chemotherapy in metastatic PDAC. Patients and Methods: The Indiana University Simon Cancer Center pancreatic cancer program was used to identify patients with metastatic PDAC who received any second-line chemotherapy. Demographic, clinical and outcomes data were collected by manual chart abstraction. Patients were divided into two groups: a NP-based treatment group and a non-NP-based treatment group. Overall (OS) and progression-free (PFS) survival were estimated using Kaplan-Meier method. Cox proportional hazards regression was used for multivariate analyses. Results: A total of 120 patients received second-line chemotherapy. There were 47 (39\%) patients in the NP group and $73(61 \%)$ in the non-NP group. As compared to the non$N P$ group, the NP group showed improved median PFS [2.8 vs. 2.1 months; hazard ratio $(H R)=0.62,95 \%$ confidence interval $(C I)=0.38-1.02 ; p=0.06]$ and median OS (7.5 vs. 4.7 months; HR=0.67, 95\% CI=0.45-1.00; $p=0.05)$. Multivariate analyses adjusted for age showed a significantly improved PFS (adjusted HR=0.60, 95\% CI=0.36-0.98; $p=0.04$ ) and a suggestion of improved $O S$ (adjusted $H R=0.67,95 \% C I=0.44$ $1.01, p=0.05$ ) in the NP group as compared to non-NP group.
\end{abstract}

This article is freely accessible online.

Correspondence to: Amikar Sehdev, MD, MPH, Assistant Professor of Medicine, Division of Hematology Oncology, Department of Medicine, Indiana University, 535 Barnhill Dr., RT 130B, Indianapolis, IN 46202, U.S.A. Tel: +1 3172740339, Fax: +1 3179489954,e-mail: asehdev@iupui.edu

Key Words: Metastatic pancreatic cancer, chemotherapy, nabpaclitaxel, overall survival, progression-free survival.
Serious adverse events were seen in $13.3 \%$ of patients in the non-NP group and $17.1 \%$ patients in the NP group. Conclusion: In a single-institution retrospective cohort study, we report a significant improvement in the PFS and suggestion of improvement in the OS with NP-based secondline chemotherapy with an acceptable toxicity rate.

Pancreatic ductal adenocarcinoma (PDAC) is a lethal cancer and is the fourth leading cause of cancer-related mortality in the United States (US) (1). In 2017 alone, 53,670 cases of PDAC are expected, resulting in approximately 43,090 deaths in the US (2). The median overall survival (OS) of patients with PDAC is $20 \%$ at 1 year and $8 \%$ at 5 years (3). Despite recent progress, there is a clear need to improve systemic treatments for PDAC. Recently, nab-paclitaxel (NP) in combination with gemcitabine (GA) was shown to lead to a clinically meaningful and significant improvement in the median OS and median progression-free survival (PFS) when compared with gemcitabine alone (4). This has led to the approval of GA as a first-line treatment for PDAC similar to FOLFIRINOX (folinic acid, 5-fluorouracil, irinotecan and oxaliplatin), the only other first-line treatment for patients with metastatic PDAC (5).

In clinical practice, many patients may receive FOLFIRINOX as first-line treatment and GA as the secondline treatment especially in the US (6). Many factors influence the decision to select between FOLFIRINOX and GA including age, performance status, associated comorbidities and potential toxicity (7). FOLFIRINOX is often chosen for patients with good performance status, age $\leq 75$ years and lack of or controlled comorbidities $(7,8)$. Usually in this scenario, GA is the preferred second-line treatment after progression on FOLFIRINOX in the absence of prospective data. Alternatively, 5-fluorouracil- based second-line therapy in combination with nanoparticle liposomal irinotecan (9) or oxaliplatin $(10,11)$ has shown OS benefit in second-line treatment. Interestingly, up to $50 \%$ of patients with PDAC may be eligible for second-line chemotherapy $(12,13)$. 
There are no randomized data for the effectiveness of GA in the second-line treatment of PDAC. However, survival benefit with acceptable toxicity has been reported by several groups with GA in patients previously treated with FOLFIRINOX $(14,15)$. Notably, these are single-institution case series with small numbers of patients, resulting in selection bias. Additionally, there was no comparison group in these studies, which leads to poor internal validity (ability to draw causal conclusion between the exposure and outcome). Therefore, we conducted a retrospective cohort study with the primary aims of assessing: i) the efficacy of NP-based (compared to non-NP-based) second-line treatment in PDAC; ii) assessing the toxicity of NP-based (as compared to non-NP-based) second-line treatment in PDAC; and iii) reviewing the existing literature for the efficacy and toxicity of NP-based second-line chemotherapy in PDAC.

\section{Patients and Methods}

Study population. The Indiana University Simon Cancer Center (IUSCC) pancreatic cancer program was used to identify the patients with biopsy-proven diagnosis of PDAC between the years 2009-2015. Retrospective as well as prospective data collection was carried out on patients with PDAC who were new to IUSCC. Main inclusion criteria of the study were age $>18$ years, diagnosis of PDAC, receipt of second-line chemotherapy treatment and available demographic, clinical and outcomes data. Patients with diagnosis of neuroendocrine pancreatic cancer were excluded. The study was approved by the Institutional Review Board of Indiana University (IRB approval number 1409274071).

Data collection. Patients were divided into two groups, NP-based treatment group and non-NP-based treatment group. Manual chart abstraction was used in addition to IUSCC cancer registry to gather the demographic, clinical and outcomes data. Both paper and electronic medical records were reviewed to obtain patient's demographic variables (age, sex, race, family history of malignancy, history of diabetes, tobacco use, alcohol use, body mass index), clinical variables including comorbidities, histology of the tumor, carbohydrate antigen (CA-19-9), bilirubin levels at presentation, location of the tumor, Eastern Cooperative Oncology Group performance status, number of metastatic sites, adjuvant chemotherapy, pathological staging (American Joint Committee on Cancer) of the tumor and whether the patient had undergone surgery or radiation therapy lastly, and outcomes variables (best response, serious toxicity, OS and PFS). Data was collected and stored in OnCore ${ }^{\circledR}$ database (Forte Research Systems, Madison, WI, USA).

Statistical analyses. Baseline characteristics between the groups that received second-line NP-based versus non-NP-based treatment were compared using chi-square test for categorical variables and Student $t$-test for continuous variables.

Response evaluation and toxicity assessment. Response was categorized based on the best response documented by the treating physician and radiology report as partial response, complete response, stable disease or progressive disease. Note that the radiological scan interval was based on clinical care. Similarly, toxicity was assessed by retrospective chart review and considered serious (grade 3 or 4 ) if the adverse effect resulted in dose reduction, dose delay or holding off of scheduled treatment. Individual toxicity assessment (type and grade) was not attempted due to the likelihood of incomplete data.

Survival and prognostic effect analyses. OS and PFS were estimated using the Kaplan-Meier method. OS was defined as the time from start of second-line treatment to death from any cause, whereas PFS was defined as the time from start of second-line treatment to either progression of PDAC or death from any cause. Survival was compared between the two groups using log-rank test. Censoring method was adopted for patients who were lost to follow-up or died. Cox proportional hazard regression model was used to estimate the simple and adjusted hazard ratios (HR) and $95 \%$ confidence interval (95\% CI), adjusting for significant variables between the two groups. $p$-Values for differences were considered significant if 0.05 or less. All statistical analyses were performed using RStudio version 1.0.143 (16).

\section{Results}

Study participants. Between 2009-2015, a total of 120 patients with PDAC were treated with second-line chemotherapy, of which 47 (39\%) were in the NP group and $73(61 \%)$ patients were in the non-NP group. The univariate analyses showed that the patients in the NP group were significantly younger as compared to the non-NP treatment group (median age $=60.4 v s$. 64 years respectively, $p=0.02$ ). Similarly, a lower percentage of patients in the NP group had diabetes mellitus at presentation as compared to the non-NP group ( $26 \%$ vs. $49 \%$ respectively, $p=0.10)$. However, none of the other demographic or clinical characteristics were significantly different between the two groups (Table I).

In the NP group, most patients received FOLFIRINOX in first-line chemotherapy (72\%) and GA in the second-line setting (77\%) (Table II). However, in the non-NP group, the most common first-line chemotherapy was GA (44\%) and 5-FU- or capecitabine- based chemotherapy was used in second-line treatment $(54 \%)$.

Response evaluation and toxicity assessment. There were no complete responses. A total of eight patients had partial response, three $(4.7 \%)$ in the non-NP group and five $(11.5 \%)$ in the NP group, respectively. Seventeen and 11 patients had stable disease in the non-NP and NP groups resulting in a disease control rate (DCR) of $31.2 \%$ in the non-NP and $36.3 \%$ in the NP group. Overall serious adverse events were observed in $13.3 \%$ of patients of the non-NP group and $17.1 \%$ of patients in the NP group.

Survival analyses. The OS analysis included 104 patients, 47 in the NP group and 73 in the non-NP group (Figure 1). The 
Table I. Baseline characteristics of patients in nab-paclitaxel- and nonnab-paclitaxel-treated groups.

\begin{tabular}{|c|c|c|c|}
\hline Variable & $\begin{array}{l}\text { Nab-paclitaxel } \\
\text { group } \\
(\mathrm{N}=47)\end{array}$ & $\begin{array}{c}\text { Non-nab- } \\
\text { paclitaxel } \\
\text { group }(\mathrm{N}=73)\end{array}$ & $p$-Value \\
\hline Median age, (range), years & $60.4(37-75)$ & $64(37-89)$ & 0.02 \\
\hline \multicolumn{4}{|l|}{ Median CA19-9 (range), } \\
\hline $\mathrm{U} / \mathrm{ml}$ & $679(1-88365)$ & $211(1-112840)$ & 0.30 \\
\hline \multicolumn{4}{|l|}{ Gender, n (\%) } \\
\hline Male & $29(24)$ & $41(34)$ & 0.60 \\
\hline Female & $18(15)$ & $32(27)$ & \\
\hline \multicolumn{4}{|l|}{ Race, n (\%) } \\
\hline White & $41(34)$ & $64(53)$ & $>0.999$ \\
\hline Other & $6(5)$ & $9(8)$ & \\
\hline \multicolumn{3}{|l|}{ Family history of any } & 0.40 \\
\hline \multicolumn{4}{|l|}{ ECOG PS, n (\%) } \\
\hline 0 & $8(17)$ & $8(17)$ & 0.64 \\
\hline 1 & $19(40)$ & $10(21)$ & \\
\hline 2 & $2(4)$ & $1(2)$ & \\
\hline \multicolumn{4}{|l|}{ History of diabetes } \\
\hline mellitus, n (\%) & $31(26)$ & $59(49)$ & 0.10 \\
\hline \multicolumn{4}{|l|}{$\begin{array}{l}\text { Location of primary } \\
\text { tumor, } \mathrm{n}(\%)\end{array}$} \\
\hline Head & $28(23)$ & $47(39)$ & 0.66 \\
\hline Body & $8(7)$ & $14(12)$ & \\
\hline Tail & $11(9)$ & $12(10)$ & \\
\hline Tobacco use, n (\%) & $26(22)$ & $36(31)$ & 0.72 \\
\hline Alcohol use, n (\%) & $31(27)$ & $38(33)$ & 0.22 \\
\hline \multicolumn{4}{|l|}{ BMI, n (\%) } \\
\hline$\leq 24.9 \mathrm{~kg} / \mathrm{m}^{2}$ & $23(19)$ & $46(39)$ & 0.21 \\
\hline $24.9-29.9 \mathrm{~kg} / \mathrm{m}^{2}$ & $18(15)$ & $17(14)$ & \\
\hline$\geq 30 \mathrm{~kg} / \mathrm{m}^{2}$ & $6(5)$ & $9(8)$ & \\
\hline Jaundice at presentation, $\mathrm{n}(\%)$ & $21(18)$ & $31(26)$ & 0.96 \\
\hline Surgery, n (\%) & $25(21)$ & $41(34)$ & 0.89 \\
\hline Adjuvant gemcitabine, n (\%) & $21(18)$ & $29(24)$ & 0.73 \\
\hline
\end{tabular}

CA19-9: Cancer antigen 19-9; ECOG PS: Eastern Cooperative Oncology Group performance status; BMI: body mass index.

median OS was significantly better in the NP group as compared to the non-NP group (7.5 vs. 4.7 months; $\mathrm{HR}=0.67 ; 95 \% \mathrm{CI}=0.45-1.00 ; p=0.05)$. Multivariate analysis adjusted for age showed a suggestion of improved OS in the $\mathrm{NP}$ group as compared to the non-NP group (adjusted $\mathrm{HR}=0.67,95 \% \mathrm{CI}=0.44-1.01, p=0.05$ ).

The PFS analysis included 104 patients, 42 in the NP group and 62 in the non-NP group (Figure 2). The median PFS was marginally improved in the NP group as compared to the non-NP group ( 2.8 vs. 2.1 months; HR=0.62; 95\% $\mathrm{CI}=0.38-1.02 ; p=0.06$ ). Multivariate analysis adjusted for age showed significantly improved PFS in the NP group as compared to the non-NP group (adjusted $\mathrm{HR}=0.60,95 \%$ $\mathrm{CI}=0.36-0.98, p=0.04)$.

\section{Discussion}

In this single-institution retrospective cohort study of 120 patients with metastatic, locally advanced or recurrent PDAC, we report a significant improvement in the PFS and suggestion of improvement in the OS with NP-based chemotherapy as compared with non-NP-based chemotherapy in the second-line treatment of PDAC. Our study is unique as we compared NP-based chemotherapy to non-NP based chemotherapy (mainly 5-FU-based) in the second-line treatment of PDAC. To our knowledge, this comparison has not been reported in any other study. Additionally, our study is the largest study examining the effect of NP-based secondline chemotherapy for PDAC in the existing literature.

In the past decade, significant progress has been made in the systemic therapy of PDAC, however, there is no current standard for the second-line treatment of PDAC. Recently, nanoliposomal irinotecan with fluorouracil and folinic acid was shown to confer a survival advantage over fluorouracil and folinic acid in patients with PDAC previously treated with gemcitabine-based therapy in a phase III, randomized controlled trial (NAPOLI-1) (9). This trial provides level 1 evidence for the use of nanoliposomal irinotecan with fluorouracil and folinic acid in patients treated with gemcitabine based chemotherapy in the first-line setting (9). However, in patients treated with first-line FOLFIRINOX, GA might be a better option as is suggested by our data and that of others $(14,15,17-19)$.

Several case series from different countries (Table III) have reported their experience with second-line GA. Although 5-fluorouracil-based chemotherapy has been studied in second-line (9-11) (Table IV), there are no randomized trials of NP-based second-line chemotherapy. Therefore, we take the opportunity to summarize the existing studies of NP-based chemotherapy in the second-line treatment of PDAC and contrast our findings with the existing literature. The summarized data argues for a randomized trial to evaluate the sequence of the two best existing options of chemotherapy (FOLFIRINOX and GA) in the treatment of PDAC to standardize first- and secondline treatment in patients who are otherwise eligible for either therapy.

We conducted a thorough English literature search on PubMed and Google Scholar using the search terms 'pancreatic cancer', 'pancreatic adenocarcinoma' or 'PDAC', and 'second-line nab-paclitaxel', 'second-line Abraxane' or 'second-line chemotherapy' until May 2017. We found a total of eight studies (Table III) reporting the experience with second-line NP in patients who were initially treated with FOLFIRINOX. Most of these studies are retrospective case series, except for the study by Portal and colleagues (14), in which they prospectively enrolled 57 patients to receive GA after progressing on FOLFIRINOX (Table III). 
Table II. Details of the first- and second-line chemotherapies in nab-paclitaxel- and non-nab-paclitaxel-treated groups.

\begin{tabular}{|c|c|c|c|c|}
\hline \multirow[t]{2}{*}{ Chemotherapy regimen } & \multicolumn{2}{|c|}{ Nab-paclitaxel group $(\mathrm{N}=47), \mathrm{N}(\%)$} & \multicolumn{2}{|c|}{ Non-nab-paclitaxel group $(\mathrm{N}=73), \mathrm{N}(\%)$} \\
\hline & First-line & Second-line & First-line & Second-line \\
\hline FOLFIRINOX & $34(72)$ & 0 & $15(21)$ & $6(8)$ \\
\hline FOLFOX/XELOX & $7(15)$ & 0 & $6(8)$ & $17(23)$ \\
\hline FOLFIRI & $1(2)$ & 0 & 0 & $5(6.8)$ \\
\hline Gemcitabine and nab-paclitaxel & $2(4)$ & $40(85)$ & $32(44)$ & 0 \\
\hline Gemcitabine & $2(4)$ & 0 & $7(9)$ & $17(23)$ \\
\hline Gemcitabine combinations $^{a}$ & 0 & 0 & $6(8)$ & $9(12)$ \\
\hline 5-Fluorouracil/capecitabine & $1(2)$ & 0 & $5(7)$ & $12(16)$ \\
\hline Other & 0 & $7^{b}(15)$ & $2^{c}(3)$ & $7^{\mathrm{d}}(9)$ \\
\hline
\end{tabular}

FOLFIRINOX: 5-Fluorouracil, leucovorin, irinotecan and oxaliplatin; FOLFOX/XELOX: 5-fluorouracil, leucovorin and oxaliplatin/ capecitabine and oxaliplatin; FOLFIRI: 5-fluorouracil, leucovorin and irinotecan. ${ }^{a}$ Gemcitabine combinations included erlotinib, capecitabine, oxaliplatin or docetaxel combined with gemcitabine. ${ }^{b}$ Included nab-paclitaxel alone $(\mathrm{N}=6)$ and nab-paclitaxel combined with pembrolizumab ( $\left.\mathrm{N}=1\right)$. ${ }^{\mathrm{c}} \mathrm{Included}$ erlotinib and oxaliplatin $(\mathrm{N}=1)$, and cyber knife therapy $(\mathrm{N}=1)$. ${ }^{\mathrm{d}}$ Included erlotinib $(\mathrm{N}=1)$, irinotecan $(\mathrm{N}=1)$, cisplatin and capecitabine $(\mathrm{N}=1)$ and phase I clinical trials [enoticumab (REGN421), idelalisib, sacituzumab govitecan (IMMU-132) or AZD6244 hydrogen sulfate; N=4].

Table III. Case series of patients receiving gemcitabine plus nab-paclitaxel after FOLFIRINOX (5-fluorouracil, leucovorin, irinotecan and oxaliplatin) for metastatic pancreatic adenocarcinoma. None of these studies had a control or comparison group.

\begin{tabular}{|c|c|c|c|c|c|c|c|c|}
\hline Study (Ref) & Country & Year & $\mathrm{N}$ & $\begin{array}{l}\text { ORR } \\
(\%)\end{array}$ & $\begin{array}{c}\text { DCR } \\
(\%)\end{array}$ & $\begin{array}{l}\text { Median } \\
\text { PFS } \\
\text { (months) }\end{array}$ & $\begin{array}{l}\text { Median } \\
\text { OS } \\
\text { (months) }\end{array}$ & $\begin{array}{l}\text { Grade } 3 \text { or } \\
4 \text { toxicity }\end{array}$ \\
\hline Salem et al. (abstract only) (22) & United States & 2014 & 12 & 8 & 24 & 3.3 & 16.2 & $\begin{array}{c}\text { Fatigue (all grades) } \\
54 \% \text { and thrombo- } \\
\text { cytopenia (all grades) 38\% }\end{array}$ \\
\hline Zhang et al. (15) & United States & 2015 & 28 & 17.9 & 46.5 & 3 & 5.3 & $\begin{array}{c}\text { Neutropenia } 17.9 \%, \\
\text { anemia } 25.0 \% \text {, thrombo- } \\
\text { cytopenia } 25 \%\end{array}$ \\
\hline Portal et al. (14) & France & 2015 & 57 & 17.5 & 58 & 5.1 & 8.8 & $\begin{array}{c}\text { Neutropenia } 12.5 \%, \\
\text { neurotoxicity } 12.5 \% \text {, } \\
\text { asthenia } 9 \%, \text { thrombo- } \\
\text { cytopenia } 6.5 \%\end{array}$ \\
\hline Bertocchi et al. (18) & Italy & 2015 & 23 & 17.4 & 43.5 & 2.7 & 5 & $\begin{array}{c}\text { Total } 13 \%, \text { thrombo- } \\
\text { cytopenia } 17.4 \%, \\
\text { neutropenia } 8.7 \%, \\
\text { anemia } 8.7 \% \text { and } \\
\text { neuropathy } 13 \%\end{array}$ \\
\hline Vogl et al. (abstract only) (23) & Austria & 2015 & 33 & NR & NR & 3 & 6.3 & $\begin{array}{c}\text { Neutropenia } 13 \%, \\
\text { thrombocytopenia } 17 \%, \\
\text { polyneuropathy } 7 \%\end{array}$ \\
\hline Caparello et al. (17) & Italy & 2016 & 71 & 7.1 & 34.2 & 2.5 & 6.2 & $\mathrm{NR}$ \\
\hline Suzuki et al. (abstract only) (24) & Japan & 2016 & 5 & 0 & 80 & 4.6 & 17 & Neutropenia $20 \%$ \\
\hline El Rassy et al. (19) & Lebanon & 2017 & 12 & 30 & 60 & 4.9 & NR & No grade $3 / 4$ toxicity \\
\hline Present study & United States & 2017 & $\begin{array}{c}\text { 120: NP: } 47 \\
\text { vs. non-NP: } 73\end{array}$ & $\begin{array}{c}11.5 \mathrm{vs} \\
4.7\end{array}$ & $\begin{array}{c}36.3 v s . \\
31.2\end{array}$ & $\begin{array}{l}2.8 v s \\
2.1 *\end{array}$ & $\begin{array}{c}7.5 \mathrm{vs} .^{\dagger} \\
4.7\end{array}$ & $\begin{array}{c}\text { Total } 17.1 \% \\
\text { vs. } 13.3 \%\end{array}$ \\
\hline
\end{tabular}

ORR, Objective response rate; DCR, disease control rate; PFS, progression free survival; OS, overall survival; NR, not reported. *Adjusted hazard ratio $(95 \%$ confidence interval $)=0.60,(0.36-0.98), p=0.04 ; \dagger$ adjusted hazard ratio $(95 \%$ confidence interval $)=0.67(0.44-1.01), p=0.05$. 


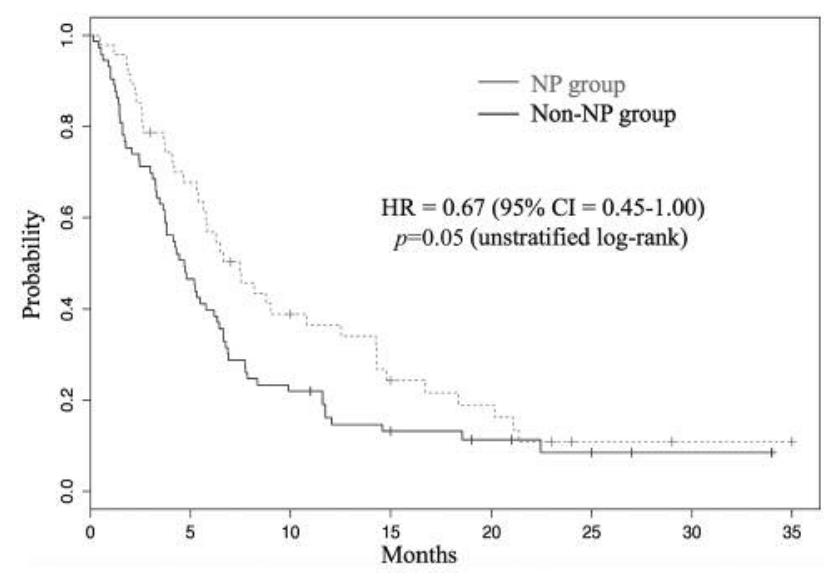

Figure 1. Kaplan-Meier survival analysis showing hazard ratio (HR) and $95 \%$ confidence interval (CI) for overall survival for nab-paclitaxel $(N P)$ - and non-NP-treated groups.

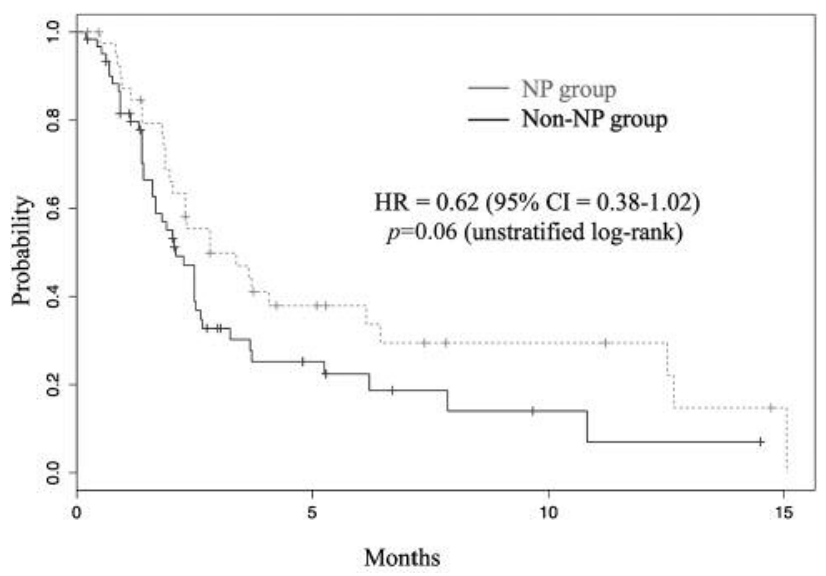

Figure 2. Kaplan-Meier survival analysis showing hazard ratio $(H R)$ and $95 \%$ confidence interval (CI) for progression-free survival for nabpaclitaxel (NP)- and non-NP-treated groups.

Table IV. Summary of phase III, randomized, controlled, studies in the second-line treatment of pancreatic ductal adenocarcinoma.

\begin{tabular}{|c|c|c|c|c|c|c|c|c|c|c|c|c|c|c|}
\hline \multirow[t]{2}{*}{ Study } & \multirow[t]{2}{*}{ Country } & \multirow[t]{2}{*}{ Year } & \multirow[t]{2}{*}{ Arms } & \multirow[t]{2}{*}{$\mathrm{N}$} & \multirow[t]{2}{*}{ ORR $(\%)$} & \multicolumn{4}{|c|}{ Median PFS } & \multicolumn{4}{|c|}{ Median OS } & \multirow[t]{2}{*}{ Grade $3 / 4$ toxicity } \\
\hline & & & & & & Months & $\mathrm{HR}$ & $\mathrm{CI}$ & $p$-Value & Months & HR & $95 \% \mathrm{CI}$ & $p$-Value & \\
\hline $\begin{array}{l}\text { Pelzer } \text { et al. } \\
\text { CONKO-01 } \\
\text { (11) } \\
\text { *Terminated early }\end{array}$ & $\begin{array}{l}\text { Germany, } \\
\text { multicenter }\end{array}$ & 2011 & $\begin{array}{c}\text { OFF } v s . \\
\text { BSC }\end{array}$ & 46 & $\begin{array}{c}\text { No } \\
\text { responses }\end{array}$ & NR & NR & NR & NR & $\begin{array}{c}4.8 \mathrm{vs} . \\
2.3\end{array}$ & 0.45 & $\begin{array}{l}0.24- \\
0.83\end{array}$ & 0.008 & None \\
\hline $\begin{array}{l}\text { Oettle } \text { et al. } \\
\text { CONKO-003 } \\
\text { (10) }\end{array}$ & $\begin{array}{l}\text { Germany, } \\
\text { multicenter }\end{array}$ & 2014 & $\begin{array}{c}\text { OFF } v s . \\
\text { FF }\end{array}$ & $168 *$ & $\begin{array}{c}\text { *1 Patient } \\
\text { R } \\
\text { in FF } \\
\text { had C }\end{array}$ & $\begin{array}{l}2.9 \mathrm{vs} . \\
2.0\end{array}$ & 0.68 & $\begin{array}{l}0.5- \\
0.94\end{array}$ & 0.01 & $\begin{array}{c}5.9 v s . \\
3.3\end{array}$ & 0.66 & $\begin{array}{c}0.48- \\
0.91\end{array}$ & 0.01 & $\begin{array}{c}\text { Anemia } 6.6 \%, \\
\text { Thrombo- } \\
\text { cytopenia } 1.3 \% \\
\text { Neuropathy } 4 \%\end{array}$ \\
\hline \multirow[t]{2}{*}{$\begin{array}{l}\text { Wang-Gillam } \\
\text { et al. } \\
\text { NAPOLI-1 } \\
\text { (9) }\end{array}$} & $\begin{array}{c}\text { Global, } \\
\text { multicenter }\end{array}$ & 2016 & $\begin{array}{c}\text { Nal-iri } 1 \\
+5-F U+ \\
\text { LLV } v s . \\
5-F U+ \\
\text { LLV }\end{array}$ & $\begin{array}{c}117 v s . \\
119\end{array}$ & $\begin{array}{c}16 v s \\
1\end{array}$ & $\begin{array}{c}2.3 v s . \\
1.4\end{array}$ & 0.68 & $\begin{array}{c}0.45- \\
0.78\end{array}$ & 0.0002 & $\begin{array}{c}6.1 \mathrm{vs} . \\
4.2\end{array}$ & 0.67 & $\begin{array}{c}0.49- \\
0.92\end{array}$ & 0.012 & $\begin{array}{c}\text { Nal-iri + 5-FU } \\
\text { + LLV: } \\
\text { Neutropenia } \\
27 \%, \text { fatigue } \\
14 \%, \text { diarrhea } \\
13 \%, \text { vomiting } \\
11 \%, \text { anemia } \\
9 \%, \text { nausea } 8 \%\end{array}$ \\
\hline & & & $\begin{array}{c}\text { Nal-iri vs. } \\
\text { 5-FU + } \\
\text { LLV }\end{array}$ & $\begin{array}{c}151 v s . \\
149\end{array}$ & $\begin{array}{c}6 v s . \\
1\end{array}$ & $\begin{array}{c}1.7 \mathrm{vs} . \\
1.4\end{array}$ & 0.82 & $\begin{array}{c}0.65- \\
1.03\end{array}$ & 0.1 & $\begin{array}{c}4.9 \mathrm{vs} . \\
4.2\end{array}$ & 0.99 & $\begin{array}{c}0.77- \\
1.28\end{array}$ & 0.94 & $\begin{array}{c}\text { Nal-Iri: Diarrhea } \\
21 \% \text {, decreased } \\
\text { appetite } 19 \%, \\
\text { neutropenia } 15 \%, \\
\text { vomiting } 14 \%, \\
\text { hypokalemia } 12 \%, \\
\text { anemia } 11 \%\end{array}$ \\
\hline $\begin{array}{l}\text { Ulrich-Pur } \\
\text { et al. } \\
(25)\end{array}$ & $\begin{array}{l}\text { Austria, } \\
\text { multicenter }\end{array}$ & 2003 & $\begin{array}{c}\text { Raltitrexed } \\
+ \\
\text { irinotecan } \\
v s . \\
\text { raltitrexed }\end{array}$ & 38 & $\begin{array}{c}16 v s . \\
0\end{array}$ & $\begin{array}{c}4 v s . \\
2.5\end{array}$ & NR & NR & NR & $\begin{array}{c}6.5 \mathrm{vs} . \\
4.3\end{array}$ & NR & NR & NR & $\begin{array}{c}\text { All } 7.9 \% ; \\
\text { Neutropenia } 21.1 \\
\text { vs. } 15.8 \% ; \\
\text { transaminases } \\
5.3 \text { vs. } 5.3 \% ; \\
\text { diarrhea } 10.5 \text { vs. } \\
\text { 10.5\%; nausea/ } \\
\text { vomiting } 5.3 \\
\text { vs. } 5.3 \%\end{array}$ \\
\hline
\end{tabular}

5-FU: 5-Fluorouracil; FF: 5-FU and folinic acid; HR: hazard ratio; OFF: oxaliplatin, folinic acid, and 5-FU 24 h; BSC: best supportive care; LLV: L-leucovorin; Nal-iri, nanosomal irinotecan; OS: overall survival; NR, not reported; CR, complete response. 
Our efficacy and toxicity results are similar to those reported in these case series. For instance, the objective response rate in the NP group of our case series was $11.5 \%$ and the DCR was $36.3 \%$, which is in line with the reported ranges of $7.1-30 \%$ and $24-80 \%$, respectively. Similarly, the median PFS (2.8 months) and the median OS (7.5 months) in our study (NP group) was consistent with the reported median PFS (range $=2.5-5.1$ months) and OS (range $=5-17$ months), respectively.

Second-line NP-based chemotherapy has been generally well-tolerated, with some studies reporting up to $25 \%$ serious (grade 3/4) adverse event rate (18). The serious adverse events usually included neutropenia (20\%), anemia (up to $25 \%$ ), thrombocytopenia (up to $25 \%$ ), neurotoxicity (up to $13 \%$ ) and asthenia (up to $9 \%$ ). We had an overall serious adverse event rate of $17 \%$, again consistent with existing literature. Notably, the adverse event rate was greater in the NP group as compared to the non-NP group $(17.1 \% \mathrm{vs}$. $13.3 \%)$. Individual toxicity assessment could not be carried out in our case series due to lack of availability of such data.

Our study has some limitations. Firstly, response evaluation was performed using the best response categorized by the treating physician, therefore, this may not be as accurate as using Response Evaluation Criteria In Solid Tumors (20). However, our results are similar to those reported in other series and we have provided robust data for OS to complement the efficacy assessment. Secondly, we were unable to provide grading for serious adverse events as per Common Terminology Criteria for Adverse Events (21) mainly because this data was not available for all our patients. However, available prospective data suggest that GA is welltolerated in the second-line treatment of PDAC. Thirdly, our study is a retrospective comparison with inherent limitations such as confounding and possibly selection bias. However, we have tried to account for confounding by carrying out multivariate analysis. Similarly, selection bias was minimized by including all patients who received second-line chemotherapy in our cohort.

\section{Conclusion}

From a single-institution retrospective cohort study, we report that NP-based chemotherapy (in combination with gemcitabine) can extend PFS and possibly OS, with an acceptable toxicity rate. Our study is unique due to its large sample size, study design and presence of a comparison group. These results are hypothesis-generating and will help clinicians to counsel patients regarding the prognosis with NP-based and non-NP-based therapy in the second-line treatment of PDAC. Our results (and others) argue for a randomized trial to evaluate the best sequence of FOLFIRINOX and GA in patients who are eligible for both chemotherapies.

\section{Funding}

Walther Cancer Foundation funding to Dr. Amikar Sehdev.

\section{Conflicts of Interest}

None.

\section{References}

1 Siegel RL, Miller KD and Jemal A: Cancer Statistics, 2017. CA Cancer J Clin 67: 7-30, 2017.

2 Surveillance, Epidemiology, and End Results (SEER) Program,. In: Cancer Stat Facts: Pancreas Cancer.

3 Miller KD, Siegel RL, Lin CC, Mariotto AB, Kramer JL, Rowland JH, Stein KD, Alteri R and Jemal A: Cancer treatment and survivorship statistics, 2016. CA Cancer J Clin 66: 271-289, 2016.

4 Von Hoff DD, Ervin T, Arena FP, Chiorean EG, Infante J, Moore M, Seay T, Tjulandin SA, Ma WW, Saleh MN, Harris M, Reni M, Dowden S, Laheru D, Bahary N, Ramanathan RK, Tabernero J, Hidalgo M, Goldstein D, Van Cutsem E, Wei X, Iglesias J, and Renschler MF: Increased survival in pancreatic cancer with nabpaclitaxel plus gemcitabine. N Engl J Med 369: 1691-1703, 2013.

5 Conroy T, Desseigne F, Ychou M, Bouche O, Guimbaud R, Becouarn Y, Adenis A, Raoul JL, Gourgou-Bourgade S, de la Fouchardiere C, Bennouna J, Bachet JB, Khemissa-Akouz F, Pere-Verge D, Delbaldo C, Assenat E, Chauffert B, Michel P, Montoto-Grillot C, Ducreux M and Groupe Tumeurs: Digestives of Unicancer and the PRODIGE Intergroup: FOLFIRINOX versus gemcitabine for metastatic pancreatic cancer. N Engl J Med 364: 1817-1825, 2011.

6 Bendell JC, Britton S, Green MR, Willey J, Lemke KE and Marshall J: Immediate impact of the FOLFIRINOX phase III data reported at the 2010 ASCO Annual Meeting on prescribing plans of American oncology physicians for patients with metastatic pancreas cancer (MPC). J Clin Oncol 29(suppl 4): abstr 286, 2011.

7 Aroldi F, Bertocchi P, Savelli G, Rosso E and Zaniboni A: Pancreatic cancer: New hopes after first line treatment. World J Gastrointest Oncol 8: 682-687, 2016.

8 Varghese AM, Lowery MA, Yu KH and O'Reilly EM: Current management and future directions in metastatic pancreatic adenocarcinoma. Cancer 122: 3765-3775, 2016.

9 Wang-Gillam A, Li CP, Bodoky G, Dean A, Shan YS, Jameson G, Macarulla T, Lee KH, Cunningham D, Blanc JF, Hubner RA, Chiu CF, Schwartsmann G, Siveke JT, Braiteh F, Moyo V, Belanger B, Dhindsa N, Bayever E, Von Hoff DD, Chen LT and Group N-S: Nanoliposomal irinotecan with fluorouracil and folinic acid in metastatic pancreatic cancer after previous gemcitabine-based therapy (NAPOLI-1): a global, randomised, open-label, phase 3 trial. Lancet 387: 545-557, 2016.

10 Oettle H, Riess H, Stieler JM, Heil G, Schwaner I, Seraphin J, Gorner M, Molle M, Greten TF, Lakner V, Bischoff S, Sinn M, Dorken B and Pelzer U: Second-line oxaliplatin, folinic acid, and fluorouracil versus folinic acid and fluorouracil alone for gemcitabine-refractory pancreatic cancer: outcomes from the CONKO-003 trial. J Clin Oncol 32: 2423-2429, 2014. 
11 Pelzer U, Schwaner I, Stieler J, Adler M, Seraphin J, Dorken B, Riess $\mathrm{H}$ and Oettle $\mathrm{H}$ : Best supportive care (BSC) versus oxaliplatin, folinic acid and 5-fluorouracil (OFF) plus BSC in patients for second-line advanced pancreatic cancer: a phase IIIstudy from the German CONKO-study group. Eur J Cancer 47: 1676-1681, 2011.

12 Smyth EN, Bapat B, Ball DE, Andre T and Kaye JA: Metastatic pancreatic adenocarcinoma treatment patterns, health care resource use, and outcomes in France and the United Kingdom between 2009 and 2012: A retrospective study. Clin Ther 37: 1301-1316, 2015.

13 Rahma OE, Duffy A, Liewehr DJ, Steinberg SM and Greten TF: Second-line treatment in advanced pancreatic cancer: a comprehensive analysis of published clinical trials. Ann Oncol 24: 1972-1979, 2013.

14 Portal A, Pernot S, Tougeron D, Arbaud C, Bidault AT, de la Fouchardiere C, Hammel P, Lecomte T, Dreanic J, Coriat R, Bachet JB, Dubreuil O, Marthey L, Dahan L, Tchoundjeu B, Locher C, Lepere C, Bonnetain F and Taieb J: Nab-paclitaxel plus gemcitabine for metastatic pancreatic adenocarcinoma after FOLFIRINOX failure: an AGEO prospective multicentre cohort. Br J Cancer 113: 989-995, 2015.

15 Zhang Y, Hochster H, Stein S and Lacy J: Gemcitabine plus nabpaclitaxel for advanced pancreatic cancer after first-line FOLFIRINOX: single-institution retrospective review of efficacy and toxicity. Exp Hematol Oncol 4: 29, 2015.

16 RStudio Team: RStudio: Integrated Development for R. RStudio, Inc., Boston, MA, USA.

17 Caparello C, Vivaldi C, Fornaro L, Musettini G, Pasquini G, Catanese S, Masi G, Lencioni M, Falcone A and Vasile E: Second-line therapy for advanced pancreatic cancer: evaluation of prognostic factors and review of current literature. Future Oncol 12: 901-908, 2016.

18 Bertocchi P, Abeni C, Meriggi F, Rota L, Rizzi A, Di Biasi B, Aroldi F, Ogliosi C, Savelli G, Rosso E and Zaniboni A: Gemcitabine plus nab-paclitaxel as second-line and beyond treatment for metastatic pancreatic cancer: a single institution retrospective analysis. Rev Recent Clin Trials 10: 142-145, 2015.
19 El Rassy E, Assi T, El Karak F, Ghosn M and Kattan J: Could the combination of Nab-paclitaxel plus gemcitabine salvage metastatic pancreatic adenocarcinoma after folfirinox failure? A single-institutional retrospective analysis. Clin Res Hepatol Gastroenterol 41: e26-e28, 2017.

20 Eisenhauer EA, Therasse P, Bogaerts J, Schwartz LH, Sargent D, Ford R, Dancey J, Arbuck S, Gwyther S, Mooney M, Rubinstein L, Shankar L, Dodd L, Kaplan R, Lacombe D and Verweij J: New response evaluation criteria in solid tumours: revised RECIST guideline (version 1.1). Eur J Cancer 45: 228247, 2009.

21 US Department of Health and Human Services: Common terminology criteria for adverse events (CTCAE) version 4.02. CTCAE_4.02_2009-09-15_QuickReference_8.5x11.pdf May 28, 2009.

22 Salem ME, Alistar AT, Dyson G, Stanski N, Mahaseth H, Choi M, Shields AF, Philip PA and Karmanos BA: Albumin-bound paclitaxel plus gemcitabine after first-line FOLFIRINOX therapy in patients with pancreatic cancer. J Clin Oncol 32(suppl): abstr e15252, 2014.

23 Vogl U, Vormittag L, Winkler T, Kafka A, Henry M, Schima W, Klaus A, Zacherl J and Ohler L: Gemcitabine plus nab-Paclitaxel in metastatic or locally inoperable pancreatic cancer - a singlecenter experience. Ann Oncol 26(Suppl 4): 52, 2015.

24 Suzuki R, Takagi T, Sugimoto M, Watanabe K, Waragai Y, Kikuchi H, Asama H, Takasumi M, Hikichi T and Ohira H: nabPaclitaxel/gemcitabine as second-line therapy after FOLFIRINOX failure in advanced pancreatic cancer. Pancreatology 16: S1eS192, 2016.

25 Ulrich-Pur H, Raderer M, Verena Kornek G, Schull B, Schmid K, Haider K, Kwasny W, Depisch D, Schneeweiss B, Lang F and Scheithauer W: Irinotecan plus raltitrexed $v s$. raltitrexed alone in patients with gemcitabine-pretreated advanced pancreatic adenocarcinoma. Br J Cancer 88: 1180-1184, 2003.

Received August 7, 2017

Revised August 26, 2017 Accepted August 29, 2017 